\title{
ПРОГРАММА РАЗВИТИЯ НАУЧНОГО ЖУРНАЛА «В МИРЕ НАУЧНЫХ OTКРЫТИЙ» = «SIBERIAN JOURNAL OF LIFE SCIENCES AND AGRICULTURE»
}

\author{
Магсумов Т.А., Максимов Я.А.
}

Цель. Разработка программы развития журнала, состоящей из комплекса взаимосвязанных мероприятий, направленных на повышение качества содержания издания, улучшение работы редакиии, усиление коммуникачии и представленности издания в академическом сообществе.

Методология. Разработка программы строится на системном подходе, с учетом внешней и внутренней среды функиионирования научной периодики. При этом базовыми в исследовании ее состояния и построении перспектив развития стали идеи Дю. Марча об обмене знаниями между стейкхолдерами деятельности журнала, необходимости постоянного привлечения новых участников, балансе между поиском нового и использованием старых проверенных методов, внимании к дисперсии результативности при выстраивании стратегий конкуренции между авторами, превращении информационных технологий в инфраструктуру деятельности редакции, при высокой развитости позволяющую журналу удержать позиции на издательском рынке.

Результаты. Журнал, посредством профилизации тематики и проведения ряда организационных мероприятий, уже смог войти в признанные узкопрофильные базы - Chemical Abstracts u Agris. Участие в предлагаемой программе, на наш взгляд, будет способствовать оптимизации и повымению эффективности деятельности издателя и редколлегии по дальнейтему научному "росту» и комплексному развитию издания, что в перспективе позволит ему войти в международные наукометрические базы более «широкого» профиля.

Область применения результатов. Являясь стратегическим руководством к изменению политики журнала, трансформации его внутренней среды и выстраивания новых форм взаимоотношений со внешней 
средой, программа может найти применение и при разработке аналогичных программ развития научных журналов.

Ключевые слова: научная периодика; научная журналистика; научная коммуникация; инноватика в организации науки; программа развития научного журнала; наука; наукометрия.

\section{IN THE WORLD OF SCIENTIFIC DISCOVERIES [SIBERIAN JOURNAL OF LIFE SCIENCES AND AGRICULTURE] DEVELOPMENT PROGRAM}

\section{Magsumov T.A., Maksimov Ya.A.}

Aim. To design the journal's development program that includes a set of interrelated activities aimed at improving both the publications content quality and the work of the editorial staff, thus enhancing communication and representation of the journal in the academic community.

Methodology. Designing the program is based on the system approach that takes into account both the external and internal environment of the functioning of scientific periodicals. The research basis to study its current state as well as prospects for the development was formed by J. March's ideas of about the exchange of knowledge between the stakeholders of the journal's activity, need for constant attraction of new participants, balance between the search for new methods and use of conventional ones, attention to the variance of effectiveness while building up competition strategies between the authors, transformation of information technology into the editorial's activity infrastructure that. Once all these elements have been improved, that can contribute to holding the journal's share of the market.

Results. The journal, through the topics profiling carrying out a series of organizational events, has already managed to enter the recognized specialized databases - Chemical Abstracts and Agris. Participation in the proposed program, in our opinion, might help to optimize and increase the activity effectiveness of both the publisher and the editorial board in terms of further scientific growth and integrated development of the journal, which in the long term could enable it to enter the international multi-discipline scientometric databases. 
Scope of application of the results. As a strategic guide to changing the journal's policy, transforming its internal environment and finding new forms of communication with the external environment, the program can be applied to design similar programs for the development of scientific journals.

Keywords: scientific periodicals; scientific journalism; scientific communication; innovation studies in the organization of science; development program of a scientific journal; science; scientometrics.

\section{1. Функционирование журнала}

\section{перед началом реализации программы}

Научно-практический многопрофильный рецензируемый журнал «В мире научных открытий» ("Siberian Journal of Life Sciences and Agriculture”) издается с целью пропаганды фундаментальных и фундаментально-прикладных региональных достижений в области медицины, биологии, сельского хозяйства и смежных дисциплин на территории Российской Федерации и за рубежом.

Исходные принципы журнала. Журнал имеет международный и междисциплинарный характер. В большинстве своем в журнале публикуются исследования, в фокусе которых находятся проблемы фундаментальных и фундаментально-прикладных исследований по клинической и профилактической медицине и медико-биологическим наукам ученых России. Но мы жестко не замыкаемся в российских рамках и публикуем работы, базирующиеся на широком сравнительном материале. Журнал стремится стать площадкой для новых ярких работ, построенных на сравнительном исследовании максимально широких по географии материалов.

Миссия журнала. Миссия журнала заключается в объединении исследовательских усилий и налаживании связей ученых в развитии научной мысли по актуальным проблемам медико-биологических и сельскохозяйственных наук, а также в обсуждении и популяризации этих областей знания, в том числе посредством предоставления открытого доступа к опубликованным статьям. Журнал ориентирован в первую очередь на актуальные региональные проблемы, которые рассматриваются в широком диапазоне: от пилотных инновационных исследований до внедрения научных разработок в практику.

Задачи журнала:

- формирование новых взглядов, опирающихся на современные научные подходы и академическую полемику различных точек зрения;

- публикация, представление и распространение научных работ рос- 
сийских и зарубежных авторов, новейшей информации и передового опыта изучения актуальных проблем медицины и биологии;

- предоставление возможности профессионального общения широкому кругу исследователей и специалистов разных областей здравоохранения, биологии и смежных наук;

- поддержка концептуальных и эмпирических дискуссий по фундаментальным и прикладным проблемам академических исследований в области медико-биологических и сельскохозяйственных наук;

- содействие развитию теоретических и практических исследований в различных областях знания;

- предоставление возможности знакомиться с актуальными научными исследованиями и разработками всем заинтересованным читателям со всего мира;

- информирование научного и профессионального сообществ об актуальных публикациях и исследовательских проектах;

- установление и укрепление научной коммуникации и связей между российскими и зарубежными учеными;

- вовлечение в академическую среду и профессиональное сообщество молодых исследователей.

Критериями отбора статей служат актуальность и общественный интерес темы, новизна предложенных идей и научная достоверность представленных материалов. Редакция журнала нацелена на обсуждение на страницах издания самых насущных вопросов в режиме корректного и аргументированного диалога, одновременной представленности разных дискурсов и разных подходов исследования. Решение о публикации статьи принимается редакционной коллегией на основе нескольких профессиональных мнений ведущих ученых в данной области, привлекаемых в качестве рецензентов и экспертов, о ее значимости, научной новизне, оригинальности и актуальности.

Аудитория журнала. Среди авторов журнала - крупные специалисты, ведущие ученые в своих областях знания, обладающие международной известностью, практикующие врачи. Журнал также предоставляет возможность публикации для аспирантов и молодых ученых (для их работ выделена отдельная рубрика). Во всех случаях статьи публикуются, исходя из критериев и политики журнала. Журнал дает авторам возможность обнародовать результаты их научных изысканий, содействуя формированию научных коллективов, объединенных вокруг исследования конкретных тем.

Политика открытого доступа. Важность проблем современного общества последовательно артикулирована не только в академическом дискурсе. 
Поэтому, кроме академической аудитории, журнал ориентирован и на неакадемических читателей, заинтересованных в обсуждении фундаментальных проблем современного общества, медико-биологических и смежных наук. Стремясь стать площадкой для широкого обсуждения этих проблем, журнал следует политике открытого доступа к публикациям. Все содержимое журнала доступно для пользователей бесплатно. Пользователям разрешается читать, скачивать, копировать, распространять, распечатывать, производить поиск, находить полные тексты статей журнала без предварительного разрешения издателя и автора.

Формат (виды) публикаций. Стремление к широкому обсуждению проблем и политика открытого доступа предполагают, что журнал стремится публиковать на своих страницах не только оригинальные научные статьи на русском и английском языках, содержащие результаты фундаментальных и теоретико-прикладных исследований в области медицины, биологии, сельского хозяйства и смежных дисциплин, но и обзорные статьи ведущих специалистов по тематике журнала, профессиональные рецензии на новые книги и научные исследования, материалы научных мероприятий, дискуссий и круглых столов, посвященные проблематике журнала.

\section{2. Цели и задачи программы}

Целью программы для научного журнала «В мире научных открытий» является повышение качества издания в соответствии с требованиями международных наукометрических баз данных с дальнейшей перспективой включения в эти базы. Реализацию мероприятий по повышению качества издания мы видим в претворении в жизнь следующих шагов:

1. рефлексия и саморазвитие редакции (выявление внутренних проблем издания и реализация комплекса действий по их устранению, включая ротацию членов редколлегии);

2. коммуникация (меры по росту аттрактивности журнала в сознании научного сообщества, модернизация сайта журнала и усиление активности в социальных сетях, дополнительная индексация журнала в ряде международных наукометрических баз (не Scopus и WoS) для увеличения уровня представленности издания для научного сообщества);

3. трансформация структуры и содержания журнала (стимулирование формирования тематических номеров, в т.ч. по материалам конференций с международным участием, международных симпозиумов и т.П., увеличение доли научных обзоров). 


\section{3. Описание программы,}

\section{механизм достижения поставленных целей и задач}

На данный момент издание провело ряд мер, которые способствовали повышению эффективности редакционной политики, улучшению качества самого издания, результатом чего стало включение в узкопрофильные наукометрические базы данных. Среди них можно отметить: изменение состава редколлегии, профилизацию издания, обязательную проверку всех поступающих статей по двум системам поиска заимствований (antiplagiat. ru и etxt антиплагиат), внедрение электронной редакции, начало практики выпуска англоязычных номеров.

В числе практических шагов по реализации поставленной цели мы видим нижеследующие, соотнесенные с задачами программы.

\section{1. Рефлексия и саморазвитие редакции}

1.1. Подача заявки на проведение экспертизы журнала Ассоциацией научных редакторов и издателей (АНРИ). Подобная экспертиза позволит получить независимую оценку содержания и формальных (издательских, библиометрических, представительских) характеристик журнала, а также рекомендации по приведению в соответствие журнала международным стандартам, если в этом есть необходимость, либо по дальнейшему продвижению журнала в глобальные индексы цитирования и другие базы данных.

1.2. Нужно сформировать особую информационную базу, в которую войдут данные о внешних и внутренних рецензентах - отечественных и зарубежных ученых, специализирующихся в соответствующих областях медико-биологических и сельскохозяйственных наук, с которыми сотрудничает журнал, и в которую могут подать заявки новые рецензенты. Рецензенты обязательно должны быть признанными специалистами в проблематике рецензируемых ими материалов, иметь в течение последних трех лет публикации в области вопросов, рассматриваемых в рецензируемой статье. Для реализации этого пункта мероприятий разработать критерии оценки для рассмотрения заявок возможных рецензентов, систему более точного подбора рецензентов по тематике статей.

1.3. Повышение требований к журналу делают насущной модернизацию в кратчайшие сроки сайта журнала. Работа в этом направлении уже ведется. Все нужные и важные сведения на русском и английском языках основная информация о журнале, данные о главном редакторе, редакции и членах редколлегии, политике журнала, правилах оформления и опубликования статей, развернутые аннотации опубликованных в журнале научных статей и обзоров, уже доступна авторам и наглядна читателям, как российским, так и зарубежным. 
1.4. Материально-техническое оснащение работы издания нуждается в улучшении. Повышение требований к научному уровню статей и качеству издания в целом, увеличившийся объем деятельности, которая связана с редакционно-издательской работой (ведение сайта журнала во Всемирной сети, профессиональный перевод на английский язык размещаемых в нем материалов, обеспечение оперативного взаимодействия с авторами, в первую очередь - путём переписки, обеспечение хранения рукописей статей, рецензий на них и иные направления организации делопроизводства), организацией независимого экспертного рецензирования поступающих в редакцию рукописей, настоятельно требуют назначения и обеспечения достойной оплаты рецензентам за работы по рецензированию поступающих материалов, осуществление основной (профильной) деятельности персоналом редакции и членами редколлегии, выплаты авторских гонораров (первоначально - хотя бы для заказанных редакцией статей).

1.5. Дальнейшее развитие международного состава редакционного совета и коллегии. В первую очередь речь идет о привлечении в состав редколлегии нескольких ученых из стран дальнего зарубежья, имеющих высокие показатели публикационной активности и цитируемости в международных наукометрических базах данных.

1.6. Юридическое сопровождение деятельности издания подразумевает разработку типовых форм различных договоров: авторских (в том числе авторского заказа), лицензионных и других.

\section{2. Коммуникация}

2.1. Существенной является деятельность, связанная с увеличением наукометрических показателей журнала. Не являясь самоцелью издания, она требует существенных стараний по повышению научного качества и уровня журнала. Это диктует необходимость добиваться непреложного соблюдения требований по научной новизне, обоснованности и достоверности, актуальности, теоретического и/или практического значения представляемых в журнал материалов. Динамика развития науки формирует подвижность проблематики и тематической структуры издания, требующая введения новых актуальных рубрик, востребованность которых читателями будет более высокой.

2.2. Наращивание глобальных научных связей предполагает дальнейшее развитие англоязычной версии журнала. С 2013 года статьи из основного журнала, получившие наивысшие оценки рецензентов, отбираются, переводятся и издаются на английском языке в переводной версии журнала: In the World of Scientific Discoveries, Series A (ISSN 2330-927X print, ISSN 23309288 online) и In the World of Scientific Discoveries, Series B (ISSN 2331-2173 
print, ISSN 2331-2181 online). На данном этапе издаются два выпуска в год на английском языке по актуальным проблемам журнала. С 2018 года в журнале In the World of Scientific Discoveries, Series A планируется издавать английские переводы текущих статей российских и зарубежных ученых по актуальным вопросам биологии и медицины, содержащих новые существенные научные результаты, а в журнале In the World of Scientific Discoveries, Series B - по актуальным вопросам сельского хозяйства.

2.3. Планируется осуществление максимальной открытости русскоязычного журнала для зарубежной аудитории посредством обеспечения регистрации англоязычного названия (в нашем случае — «Siberian Journal of Life Sciences and Agriculture») и публикации детальной информации об издании и всех статьях на английском языке.

В перспективе продумываем стратегию дальнейшего развития и продвижения параллельного издания «Siberian Journal of Life Sciences and Agriculture» на английском языке в электронном (онлайн) виде на англоязычном сайте журнала, содержащего в свободном доступе оригинальные, а не дублирующие (переводные), научные статьи; расширение издательского портфеля, улучшение полиграфии и дизайна издания и т.п.

2.4. Одна из основных целей развития журнала - интеграция в мировое научное сообщество. Изучив возможности и потенциал издания, можно выделить два ключевых курса по его продвижению: распространение (посредством, прежде всего, подписки, а также продажи выпусков) и включение в различные базы данных научных журналов. Необходимо составление списка подходящих для журнала партнеров, баз данных и репозиториев. Полнотекстовые номера журнала должны присутствовать на важнейших мировых платформах электронных ресурсов, в том числе и на российских, что усилит охват «внутренней» русскоязычной аудитории, таких как: ИАС «Наука-МГУ» («Истина»), DOAJ, КиберЛенинка и др.

Для учета текущих научных результатов создавать открытые ресурсы для архивирования авторских публикаций (препринтов) с соблюдением процедуры рецензирования - вариант arxiv.org, с идентификацией отчета (DOI) и автора (ORCID).

2.5. Продвижение журнала через современные цифровые каналы - в сервисах Apple Store и Google Play в виде отдельных приложений. Такой формат открытого доступа представляется наиболее эффективным сегодня.

2.6. Осуществление перехода на модель открытого доступа, наравне с несомненными издержками, принесло очевидные преимущества. Недостатки касаются материально-финансовых аспектов деятельности издателя и редакции - они лишаются дохода от читательской подписки и продажи пе- 
чатных выпусков журнала. Одновременно открытый доступ дает возможность значительно нарастить аудиторию читателей, увеличить вероятность цитируемости статей и роста наукометрических показателей их авторов, что и является основной задачей. Редакция считает, что используемая платформа Open Journal System является эффективным и удобным инструментом подготовки и широкого распространения журнала.

\section{3. Трансформация структуры и содержания журнала}

3.1. Поскольку особые требования международных баз предъявляются к библиографии, с целью правильной работы механизма цитирования статей, а соответственно, и формирования на его основе рейтингов, планируется дальнейшее качественное совершенствование представленных авторами списков литературы на основе привычных стандартов и международных - с использованием транслита.

3.2. В ближайших планах редакции - дополнительное усиление требований к структуре, увеличению объема и содержания расширенной англоязычной аннотации для русскоязычных статей. Такой полноценный абстракт позволит облегчить работу с журналом иностранным авторам.

3.3. В целях актуализации тематики публикаций и формирования привычного образа в глазах читателей журнал стремится к стабилизации структурного наполнения номеров. В частности, считаем обязательным наличие в каждом номере как минимум одного обзора (это стабильная форма для медицинского издания международного уровня), через номер - профессиональной рецензии, причем хотя бы в четверти случаев - на зарубежные работы.

3.4. Обязательным считаем не только англоязычные, но и тематические номера, посвященные узкой проблеме. При этом такие номера, на наш взгляд, могут отражать результаты исследований коллективов по крупным грантам, представлять итоги международных симпозиумов или работы специально подобранных и приглашенных отдельных исследователей, признанных специалистов в одной проблеме.

\section{4. План реализации программы развития научного журнала}

1. Вступление в Ассоциацию научных редакторов и издателей (АНРИ). АНРИ дает возможность защищать интересы научного журнала или издательства на российском и международном уровнях.

2. Проведение экспертизы журнала Ассоциацией научных редакторов и издателей (АНРИ). Подобная экспертиза позволит получить независимую оценку содержания и формальных (издательских, библиометрических, представительских) характеристик журнала, а также рекомендации по приведению в соответствие журнала международным стандартам, 
если в этом есть необходимость, либо по дальнейшему продвижению журнала в глобальные индексы цитирования и другие базы данных [3].

3. Вступление в Международный комитет по публикационной этике COPЕ. Следование международным стандартам этики научных публикаций.

4. Разработка базы данных, содержащей информацию о внешних и внутренних рецензентах (российских и зарубежных), ее регистрация в Роспатенте.

5. Подписная кампания, включая подписку на журнал в российском сегменте рынка, а также на рынках стран СНГ и дальнего зарубежья. Данная статья расходов также подразумевает распространение журнала в крупные российские (РГБ, РНБ, ГПНТБ России, БЕН РАН, ГПНТБ СО РАН, ФГБНУ ЦНСХБ) и зарубежные библиотеки и организации;

6. Присвоение и регистрация DOI. DOI - это новейший стандарт обозначения и представления информации в Глобальной сети Интернет, который активно применяется, в том числе, всеми крупнейшими мировыми научными издательствами. Система идентификации DOI используется «для однозначного обозначения объектов информационной деятельности при применении, главным образом, в сфере электронных документов» [1; с. III].

7. Разметка журнала в РИНЦ, на сайте электронной редакции OJS и других системах индексации и электронных ресурсов. Развитие, поддержка и продвижение электронной версии научного журнала.

8. Редакционно-издательская деятельность. Включает в себя: дизайн и верстку, учитывающие все современные требования к научной периодике; подготовку макета и техническое редактирование; корректуру; научное и литературное редактирование; изготовление тиража; координацию производства.

9. Заказные статьи и обзоры по актуальным проблемам (тематический номер). Внедрение заказных статей и обзоров по актуальным проблемам. Периодическое введение в практику тематических номеров с приглашением ведущих исследователей по отобранным темам.

10. Рещензирование. Существует необходимость в привлечении в основном зарубежных рецензентов по тематике рецензируемых материалов.

11. Интернет-сервис «Антиплагиат». Проверка рукописей и статей сразу несколькими сервисами и программами обнаружения заимствований и плагиата, в том числе посредством российского проекта «Антиплагиат», который реализует «технологию проверки текстовых документов на наличие заимствований из общедоступных сетевых источников» [2].

12. Развитие и продвижение параллельного издания «Siberian Journal of Life Sciences and Agriculture» на английском языке в элек- 
тронном (онлайн) виде, включающего в свободном доступе оригинальные, а не дублирующие (переводные), научные статьи.

13. Архивирование авторских публикаций в различных сетевых каталогах и библиотеках (DOAJ, КиберЛенинка, РГБ, НЭИКОН, НЭБ, LOCKSS, WorldCat и др.).

14. Продвижение в современных цифровых каналах и на платных электронных ресурсах, в первую очередь - в сервисах Apple Store и Google Play в форме самостоятельных приложений, что является на данный момент одним из наиболее эффективных способов распространения информации.

\section{5. Перспективы развития научного журнала}

Перспективы журнала, после комплекса мер по трансформации его структуры, усиления редакционной политики и увеличения коммуникационного пространства, видятся в:

1. увеличении потока статей, что позволит производить более качественный отбор материала, расширить «географию» авторов, повышая качественный уровень издания и расширяя территориальный охват;

2. увеличении доли переводных статей и появлении зарубежных авторов (не из стран СНГ), облегчая восприятие журнала за рубежом;

3. росте подписки на журнал на российском и зарубежном сегментах;

4. расширении индексирования в базах данных и увеличении числа отрытых платформ и ресурсов, где присутствует журнал;

5. стабилизации структуры журнала, которая станет привычной для авторов и читателей, и будет включать не только оригинальные статьи, но обзоры и рецензии, в том числе по новейшим зарубежным достижениям и разработкам, что повысит информационную привлекательность журнала как канала получения новейшей и актуальной информации;

6. подаче заявки на вступление в Международный комитет по публикационной этике СОРЕ;

7. расширении штата профессиональных переводчиков журнала с одной до двух штатных единиц;

8. проведении периодической ротации членов редколлегии в соответствии с показателями публикационной активности и цитируемости в ведущих международных наукометрических базах, проверок на предмет нарушения публикационной этики;

9. расширении сотрудничества со сложившимися научными коллективами и общественными организациями с перспективой превращения тематических номеров в стабильные серии журнала. 


\section{6. Дальнейшее финансирование журнала}

Финансирование деятельности журнала осуществлялось и осуществляется ООО «Научно-инновационный цент», который является учредителем журнала.

По окончанию реализации проекта учредитель будет стремиться к дальнейшему повышению намеченных показателей, усиливая привлекательность издания в глазах научного сообщества - авторского и читательского. Это, в свою очередь, сделает положение журнала более стабильным на рынке издательских услуг.

Показателем стабильности функционирования издания является его десятилетняя история, за время которой издание прошло путь от мультидисциплинарного до узкопрофильного по тематике журнала с большим контингентом читателей и авторским редакционным портфелем, позволяющим проводить отбор публикаций по качеству и тематике без ущерба для его периодичности.

\section{Список литературы}

1. ГОСТ Р ИСО 26324-2015. Система дискретных идентификаторов объекта [Текст] $=$ Digital object identifier system : национальный стандарт : издание официальное : введен впервые : дата введения 2016-07-01 : утвержден и введен в действие Приказом Федерального агентства по техническому регулированию и метрологии от 11 ноября 2015 г. № 1750-ст / подготовлен ВИНИТИ РАН. - М.: Стандартинформ, 2016. - IV, 13, [1] с. - (Система стандартов по информации, библиотечному и издательскому делу $=$ System of standards for information, librarianship and publishing).

2. О системе / Антиплагиат [Электронный ресурс] // Режим доступа: https:// www.antiplagiat.ru/page/about, свободный (дата обращения 26.11.2017).

3. Экспертиза научных журналов / Ассоциация научных редакторов и издателей [Электронный ресурс] // Режим доступа: http://rasep.ru/uslugi-anri/ application, свободный (дата обращения 26.11.2017).

\section{References}

1. Federal Agency for Technical Regulation and Metrology, (2016). " GOST R ISO 26324-2015. Sistema diskretnykh identifikatorov ob'ekta», Natsional'nyi standart ot 11 noyabrya 2015 g. № 1750-st [“GOST R ISO 26324-2015. Digital object identifier system”, National standard of November 11, 2015 No. 1750-st]. [online] Moscow: Standartinform.

2. Ekspertiza nauchnykh zhurnalov [Examination of scientific magazines], (2017). [online] Assotsiatsiya nauchnykh redaktorov i izdatelei. Available at: http:// rasep.ru/uslugi-anri/application [Accessed 26 Nov. 2017]. 
3. O sisteme [About system], (2017). [online] Antiplagiat. Available at: https:// www.antiplagiat.ru/page/about [Accessed 26 Nov. 2017].

\section{ДАННЫЕ ОБ АВТОРАХ}

Магсумов Тимур Альбертович, кандидат исторических наук, доцент, доцент кафедры истории и методики ее преподавания; старший научный сотрудник лаборатории мировых цивилизаций

Набережночелнинский государственный педагогический университет; Международный сетевой иентр фундаментальных и прикладных исследований

ул. Низаметдинова, 28, г. Набережные Челны, 423806, Российская Федераиия; ул. Горького, 89а, офис 4, г. Сочи, 354000, Российская Федерация nabonid1@yandex.ru

Максимов Ян Алексеевич, директор издательства

Научно-инноваиионный иентр

ул. 9 Мая, 5/192, г. Красноярск, 660127, Российская Федерация mik_kras@mail.ru

\section{DATA ABOUT THE AUTHORS}

Magsumov Timur Al'bertovich, Ph.D. in History, Associate Professor, Associate Professor of History and its Teaching Methods Department; Senior Researcher of the Laboratory for World Civilizations

Naberezhnye Chelny State Pedagogical University; International Network Center for Fundamental and Applied Research

28, Nisametdinov Str., Naberezhnie Chelny, 423806, Russian Federation; 89a, office 4, Gorky Str., Sochi, 354000, Russian Federation SPIN-code: $1329-1458$

ORCID: 0000-0003-0117-7513

ResearcherID: I-5300-2013

Scopus Author ID: 55799874500

Maksimov Yan Alekseevich, Director of the Publishing House

Science and Innovation Center Publishing House

5/192, 9 Maya Str., Krasnoyarsk, 660127, Russian Federation

SPIN-code: 1906-4770

mik_kras@mail.ru 